\title{
Glucagon-like peptide 1 and type 2 diabetes: Targets and new therapies
}

\author{
Robab Sheikhpour \\ Department of Biology, Science and Research Branch, Islamic Azad University, Tehran, Iran \\ sheikhpour_r@yahoo.com
}

\begin{abstract}
Glucagon-like peptide 1 (GLP-1) is an incretin hormone which is released from gut. It stimulates insulin secretion, suppresses glucagon secretion and the combined effects on insulin and glucagon secretion result in inhibition of hepatic glucose production, which importantly contributes to the glucose lowering effect of the hormone. It seems GLP-1 can be used in treatment of diabetic patient but because of its rapid elimination by DPP-4, is not suitable for clinical use. Therefore two strategies have been used to exploit the beneficial actions of the hormone (i) development of more stable activators of the GLP-1 receptor so-called GLP-1 mimetics like exenatide, Liraglutide and (ii) inhibitors of DPP-4 like sitagliptin, vildagliptin and saxagliptin. These components can be used in monotherapy or in combination with metformin, insulin, sulphonylurea. The pathophysiological bases of these therapeutics are reviewed in this article.
\end{abstract}

Keywords: GLP-1, diabetes, GLP-1 mimetics, DPP-4 inhibitor.

Introduction

The prevalence of diabetes mellitus (DM) is reaching epidemic levels worldwide (Akansha Mishra et al., 2009; Jali \& Hiremath, 2010; Pushpa et al., 2011; Venkatesan et al., 2011). More than 200 million people have type 2 diabetes mellitus (T2DM) and the numbers continue to rise and have reached an epidemic proportion (Wild et al., 2004). The total number of people with diabetes is expected to reach 370 million worldwide in 2030. Contributing to its increased prevalence is the problem of obesity, the major risk factor for T2DM. It is now one of the most challenging healthcare problems. Currently available therapy acts by increasing insulin secretion (sulphonylurea and glinides), decreasing insulin resistance (glitazones and metformin) or delaying the absorption of glucose from the intestine (acarbose). None of these drugs have been shown to stop the progressive decline of beta-cell function, and none address the elevated glucagon secretion. Oral anti-diabetic drugs (OADs) are associated with side effects such as weight gain, hypoglycaemia, lactate acidosis and peripheral oedema. After some years most of the subjects with T2DM need insulin treatment for control of hyperglycaemia. Insulin treatment is expensive and troublesome for the patients, and also induces weight gain. Given this background, there is a need for new classes of blood-glucose-lowering drugs that minimise the risk of hypoglycaemia (Madsbad, 2009). Incretinbased therapy is the latest marketed development in this field (Tahrani et al., 2010).

Incretins

Incretins amplify insulin secretion, an effect that is observed when glucose is taken orally (as opposed to infused intravenously) in amounts that result in identical increases in plasma glucose concentrations (Vilsboll \& Holst, 2004). The effect can therefore be presented as the ratio between the areas under the oral and intravenous insulin concentration curves and in healthy subjects given $75 \mathrm{~g}$ glucose orally, amount to an approximately three fold increase in insulin secretion. The

Review article

CCIndian Society for Education and Environment (iSee) "GLP-1"

http://www.indjst.org amplification is caused by incretin hormones released from gut, which potentiate glucose-induced insulin secretion from the pancreatic $\beta$-cells. The incretin effect is based predominantly on the secretion of two known gut hormones with insulinotropic properties, GLP-1 and glucose dependent insulinotropic polypeptide (GIP) also referred to as gastric inhibitory polypeptide (Combettes, 2006; Holst et al., 2008).

Glucagon-like peptide 1 (GLP-1)

Glucagon-like peptide 1 is a 30 amino acid peptide produced in the endocrine L-cells of the intestinal epithelium (Holst, 2007). The GLP-1 is liberated from proglucagon by the action of pro-hormone convertase $1 / 3$ (PC1/3). Its secretion is post prandially induced and increases in proportion to the size of the meal (10-30 pM), although basal secretion of GLP-1 is observed even in the fasting state (5-10 pM). Post prandial secretion is biphasic: the early phase begins within a few minutes and lasts up to $60 \mathrm{~min}$, this is followed by a second phase continuing up to $120 \mathrm{~min}$ after a meal. The secretion of GLP-1 into the circulation is stimulated by ingestion of carbohydrate, protein and fat. Carbohydrate ingestion is the best stimulus for GLP-1 secretion in both animals and humans, however only the mechanism of action for glucose and fructose is beginning to be elucidated (Combettes, 2006). GLP-1 is degraded by DPP-4 and the products GLP-1 [9-36 amide] are biologically inactive. The half-life of GLP-1 is less than 2 minutes (Wua et al., 2009).

GLP-1 has a number of functions: it enhances insulin gene expression, insulin biosynthesis and stimulates insulin secretion (Marfellaa et al., 2010). In addition, it has trophic and protective actions on b-cells in vitro and in vivo, where it increases $\beta$-cell proliferation, induces neogenesis from precursor cells in the pancreatic ducts and reduces apoptosis which is induced by cytokines, lipids or high glucose levels (Drucker, 2006). The antiapoptotic effect of GLP-1 has also been clearly demonstrated in human $\beta$-cells. Furthermore, GLP-1 strongly inhibits glucagon secretion and the combined R.Sheikhpour
Indian J.Sci.Technol. 
effects on insulin and glucagon secretion result in inhibition of hepatic glucose production, which, importantly, contributes to the glucose lowering effect of the hormone. GLP-1 increases glucose uptake in muscle and enhances lipogenesis in adipose tissue. Also GLP-1 suppresses appetite, food intake, decelerates gastric emptying and induces satiety leading to weight loss if administered for weeks or months. Finally, GLP-1 seems to have beneficial actions on the cardiovascular system, enhancing myocardial performance in experimental and clinical cardiac insufficiency reducing infarct size in experimental myocardial infarction and improving endothelial dysfunction in patients with T2DM. In high concentrations, it causes nausea and eventually vomiting (Urusova et al., 2004; Holst, 2007; Holst et al., 2008) .

The mechanism of GLP-1 in insulin secretion: GLP-1 potently stimulates insulin secretion in a strictly glucosedependent manner.GLP-1 is connected to its receptors in the pancreas. The GLP-1 receptor is coupled to the Gprotein Gs which stimulates the adenylyl cyclase system, thereby increasing intracellular cAMP levels and resulting in the activation of protein kinase $A(P K A)$, activation of protein kinase $A$ and the CAMP regulated guanine nucleotide exchange factor II leads to membrane depolarization and an increase in intracellular $\mathrm{Ca}^{2+}$, resulting from the opening of $\mathrm{Ca}^{2+}$ channels (PKA' pathway) and the mobilization of intracellular $\mathrm{Ca}^{2+}$ stores , ultimately resulting in insulin exocytosis (Holst \& Deacon, 2004).

Glucose dependent insulinotropic polypeptide (GIP): Glucose dependent insulinotropic polypeptide, formerly known as gastric inhibitory polypeptide, is a product of the pro GIP gene is produced into endocrine K-cells which are most abundant in the proximal small intestine (Holst \& Deacon, 2004). PC1/3 is responsible for the processing of pro-GIP in addition to that of pro-glucagon (Ugleholdt et al., 2006). GIP is one of the substrates for the ubiquitous proteolytic enzyme DPP-4 (Nauck \& Meier, 2005). GIP might increase to levels that are five times that of GLP-1, it follows that GLP-1 is a more potent stimulator of insulin secretion (Fehmann et al., 1995; Vilsboll et al., 2003). It is important to note that the actions of both hormones, which are mediated by interaction with specific G-protein coupled receptors on the $b$-cells of the islets of Langerhans. The actions of GIP seem to be similar to those of GLP-1 in b cells. GIP is a powerful stimulator of insulin secretion. But unlike GLP-1, GIP stimulates glucagon secretion (Holst et al., 2008). GIP has no effect on the gastrointestinal system or on food intake, but might have a role in metabolism by enhancing the peripheral deposition of lipids (Holst et al., 2008). The insulinotropic effect of GLP-1 is retained in T2DM patients whereas that of GIP is almost completely lost (Holst et al., 2008).

\section{GLP-1 based therapies for type 2 diabetes}

GLP-1, after injection or infusion, is rapidly degraded by the ubiquitous enzyme DPP-4. It cleaves the two N- terminal amino acids of GLP- 1 and renders the molecule inactive with respect to insulin secretion (Deacon et al., 1995). This occurs with a rapidity that leaves the hormone with an apparent plasma half-life of $<2$ min (Deacon et al., 2000; Vilsboll et al., 2003). Because of its rapid elimination natural GLP-1 is unsuitable for clinical use (and continuous infusion is, for various reasons, not optimal). Therefore two strategies have been pursued to exploit the beneficial actions of the hormone: (i) development of more stable activators of the GLP1receptor (so-called incretin or GLP-1 mimetics) and (ii) inhibitors of DPP-4 (Holst et al., 2008).

\section{GLP-1 mimetics}

In this section, two classes of GLP-1 mimetics are introduced.

Exenatide( Byetta): Exenatide is a glucagon-like peptide 1 (GLP-1) receptor agonist that was approved in 2005 in the United States as adjuvant therapy for the treatment of T2DM (Faludi et al., 2009). The American Association of Clinical Endocrinologists now recommends exenatide as an option for patients who do not achieve control with oral treatment (Chen et al., 2006). Exenatide is a 39 amino acid peptide, a synthetic version of the naturally occurring hormone exendin- 4 which is a peptide with $53 \%$ sequence homology to GLP-1, in its first 30 amino acids, from the Gila Monster lizard (Nielsen, 2005; Madsbad, 2009). Exendin-4 differs from GLP-1 in several aspects: (i) it has a longer half-life (pharmacologic action lasting 6 h) because it does not serve as a substrate for dipeptidyl peptidase IV, which quickly metabolizes GLP-1; (ii) it has greater insulinotropic efficacy (Urusova et al., 2004). Also it can be administered therapeutically as a twice daily subcutaneous injection in vitro.

Exenatide has been shown to bind to and activate the GLP-1 receptor of rat islet cells (Bradley \& Kulstad, 2010). Exenatide have been demonstrated to induce insulin gene transcription as well as to promote b-cell mass by enhancing proliferation / neogenesis and by reducing $\beta$-cell apoptosis (Chen et al., 2006). This antiapoptotic action of exendin- 4 is associated with reduced synthesis of caspase- 3 , caspase- 8 and caspase- 9 and with decreased release of cytochrome $\mathrm{C}$ from the mitochondria (Winzell \& Ahrén, 2007). Also it enhances glucose- dependent insulin secretion, inhibits glucagon secretion and reduces hemoglobin A1c. It slows gastric emptying, reduces food intake and decreases weight (Mayhew, 2008). Exenatide also reduces many important cardiovascular risk factors and blood pressure (Urusova et al., 2004). Side-effects are primarily nausea and vomiting (Holst et al., 2008).

\section{Exenatide therapy}

Clinical studies using Byetta have demonstrated sustained effects on $\mathrm{HbA} 1 \mathrm{c}$, body-weight reduction and improved b-cell function in patients with T2DM. In this study, treatment with exenatide showed a statistically significant difference in $\mathrm{HbA} 1 \mathrm{c}$ (a decline of $1 \%$ from baseline in favor of exenatide; baseline $\mathrm{HbA} 1 \mathrm{c}=8.2 \%$ ) 
and significant weight loss. The observed weight loss was progressive (Holst et al., 2008). Zinman and co-workers compared exenatide with placebo in T2DM patients treated with a combination of glitazone and metformin for 16 weeks. HbA1c (baseline: $7.9 \%$ ) was reduced by $1.0 \%$ point and weight by $1.6 \mathrm{~kg}$ compared with placebo treatment. No clinically significant episodes of hypoglycaemia were reported (Zinman et al., 2007). As in most of the other studies, the drop-out rate in the exenatide group was twice as that in the placebo group (29\% vs $14 \%$ ) (Zinman et al., 2007).

In two open-label trials, exenatide was compared with insulin treatment in patients inadequately controlled by metformin plus sulphonylurea. In the first study, 551 patients were randomised to receive glargine once daily or exenatide twice daily. After 26 weeks, $\mathrm{HbA1c}$ fell by $1.1 \%$ points in both groups (baseline: $8.2 \%$ ) (Heine et al., 2005). Exenatide reduced post-prandial glucose excursions more than insulin glargine, while insulin glargine had a more pronounced effect on fasting plasma glucose. Body weight increased, as expected, by $1.8 \mathrm{~kg}$ with glargine while a $2.3 \mathrm{~kg}$ weight loss was obtained with exenatide. Frequencies of hypoglycaemia did not differ between treatments, but nocturnal hypoglycaemia was less frequent with exenatide. In the exenatide and glargine group $19.4 \%$ and $9.7 \%$ of the patients, respectively, withdrew from the study. The mean daily dose of insulin glargine at the study end was 26 units indicating that exenatide efficacy may be equivalent to a mean daily dose close to that. In the second 52-week trial, exenatide was compared with twice daily biphasic insulin aspart (baseline: HbA1c 8.6\%). A greater proportion of exenatide-treated patients reached $\mathrm{HbA} 1 \mathrm{c}$ $<7.0 \%$ (32\% vs. $24 \%$ ). Body weight changes ( $-2.5 \mathrm{~kg}$ vs. $2.9 \mathrm{~kg})$ Systolic $(-5 \mathrm{mmHg})$ and diastolic $(-2 \mathrm{mmHg})$ blood pressures were significantly reduced with exenatide, but remained unchanged with insulin (Nauck et al., 2007). No difference with respect to hypoglycaemia was found between the two groups. Exenatide also improved $\beta$-cell function when added to metformin (Bunck et al., 2009).

In a 52-week trial that included 69 metformin-treated patients, the impact of exenatide on beta-cell function (measured by arginine-stimulated hyperglycemic clamp) was compared to those of insulin glargine. A 52 week treatment with exenatide produced a 2.46 fold increase in glucose and arginine-stimulated $\mathrm{C}$ peptide secretion compared with insulin glargine (Tahrani et al., 2010). In a study, exendin-4-treated mice also had delayed onset of diabetes, exhibiting lower levels of hyperglycemia and higher levels of insulin (Urusova et al., 2004). In another study, in type 2 diabetic patients, a remarkable weight loss had been observed with both exenatide and liraglutide, in comparison with control treatments (Mannucci \& Rotella, 2008).

Liraglutide: Another incretin mimetic currently under clinical development is liraglutide which is based on the structure of native human GLP-1 but modified to include an amino acid substitution and an attachment of a C16 acyl chain , (Knudsen et al., 2000) enabling the molecule to bind to albumin, thereby preventing renal elimination and degradation by DPP-4. It is slowly absorbed, with maximal concentration after 10-14 $\mathrm{h}$ and a half-life of 11$13 \mathrm{~h}$, (Agerso \& Vicini, 2003) making it suitable for oncedaily injection. Liraglutide has similar actions to those of continuously infused GLP-1 and seems to have a clinical potential similar to that of exendin-4. Liraglutide has been reported to have multiple glucoregulatory actions, reducing hyperglycemia (through stimulation of insulin secretion, suppression of inappropriate glucagon secretion), slowing of gastric emptying, losing body weight and improving b-cell function in patients with T2DM (Nielsen, 2005; Holst et al., 2008). Adverse reactions after liraglutide administration are similar to those observed after administration of native GLP-1 and included nausea and, more rarely, vomiting and headaches.

Liraglutide therapy

In a study with 11 subjects with T2DM, a single liraglutide injection $(10 \mu \mathrm{g} / \mathrm{kg})$ resulted in the reduction of fasting plasma glucose over $12 \mathrm{~h}$ and subsequently suppression of glucose excursions and slowing of gastric emptying after a meal; beneficial effects on insulin secretion and glucagon suppression post meal were also reported. Nausea was the most common treatmentrelated adverse event noted (Madsbad et al., 2004). Another study reported that liraglutide suppressed postprandial glucose excursions, reduced fasting plasma glucose concentrations, enhanced first-phase insulin response after meals and suppressed postprandial plasma glucagon concentrations (Nielsen, 2005). In a clinical study, 33 patients with T2DM were treated with liraglutide $(0.6 \mathrm{mg} /$ day $)$ or placebo for 8 weeks.

Liraglutide treatment was associated with a decrease in $\mathrm{A} 1 \mathrm{C}(-0.8 \% ; \mathrm{p}=0.028)$ and fasting serum glucose $(-2.2$ $\mathrm{mmol} / \mathrm{l} ; \mathrm{p}=0.002$ ) compared with placebo. Furthermore, insulin sensitivity increased $(p=0.015)$ and gastric emptying appeared to be unaffected. Transient episodes of nausea and diarrhea were the most frequent adverse events associated with liraglutide exposure; hypoglycemia was not observed (Harder et al., 2004). In a study, Liraglutide $(1.2$ and $1.8 \mathrm{mg}$ ) reduced $\mathrm{HbA} 1 \mathrm{c}$ more than glimepiride and more of the subjects in the liraglutide groups reached $\mathrm{HbA} 1 \mathrm{c}$ level of $<7.0 \%$. In addition, the decrease in $\mathrm{HbA} 1 \mathrm{c}$ with liraglutide $(1.8 \mathrm{mg})$ was significantly greater than with liraglutide $(1.2 \mathrm{mg})$. The decrease in $\mathrm{HbA} 1 \mathrm{c}$ was most pronounced in the group previously treated with only lifestyle changes (liraglutide $1.2 \mathrm{mg}: 1.2 \%$ point, liraglutide $1.8 \mathrm{mg}: 1.6 \%$ point and glimepiride: $0.9 \%$ point).

At the end of the study, there was a significant weight decrease in the liraglutide groups as compared to weight gain in the glimepiride group, resulting in a weight difference of $3.2-3.6 \mathrm{~kg}$ between the liraglutide groups and glimepiride-treated patients. Nausea occurred in $29 \%$ 
of the participants in the liraglutide groups, but was transient, compared with $9 \%$ in the glimepiride group (Garber et al., 2009). In another study, patients treated with metformin or sulphonylurea or a combination of metformin and sulphonylurea were directly randomised to once-daily liraglutide or twice-daily exenatide (Byetta). This 26-week study, provided a direct comparison between the two GLP-1 analogues, included 464 people with T2DM. The basal HbA1c was slightly above $8 \%$. The patients treated with liraglutide achieved a reduction in $\mathrm{HbA} 1 \mathrm{c}$ of more than $1.1 \%$ point, compared to a reduction in $\mathrm{HbA} 1 \mathrm{c}$ of less than $0.8 \%$ point in the exenatide-treated group, a difference which was statistically significant.

In the liraglutide group, $55 \%$ reached an $\mathrm{HbA} 1 \mathrm{c}$ level of $<7 \%$, compared to $45 \%$ in the exenatide group, which was significantly different. For an $\mathrm{HbA} 1 \mathrm{c}<6.5 \%$ the number was $35 \%$ and $20 \%$, respectively. Both groups lost around $3 \mathrm{~kg}$ in weight, with a trend towards more weight loss in the liraglutide group. Among the patients previously treated with metformin alone, this difference was $1 \mathrm{~kg}$ in favour liraglutide (not statistically significant). The most frequently reported adverse events for both liraglutide and exenatide were nausea at a level of about $25 \%$ (percentage of all study participants reporting nausea at least once). After week 8- 10 the percentage of patients reporting nausea with liraglutide was below $10 \%$, while in the exenatide group, the level remained about $10 \%$. The rate of minor hypoglycaemia was statistically significantly lower in the liraglutide group, but the overall rate was low for both the groups (Madsbad, 2009).

In another clinical study, liraglutide (1.9 mg once daily) was added to either glimepiride or metformin for 26 weeks in 2132 patients. Combination therapy with metformin + liraglutide reduced $\mathrm{HbA} 1 \mathrm{c}$ similar to metformin plus glimepiride (approximately $1.0 \%$ point) with minimal risk of hypoglycaemia. The combination of liraglutide and glimepiride lowered $\mathrm{HbA} 1 \mathrm{c}$ significantly more than glimepiride plus rosiglitazone (Madsbad et al., 2004).

\section{DPP-4 inhibitors in improvement of glycaemia}

DPP-4 is a serine exopeptidase or serine aminopeptidase found at numerous tissue (Yong Jin et al., 2010), including the kidney, intestinal brush-border membranes, hepatocytes and on endothelial cells, especially in the microvascular circulation. DPP-4 plays a pivotal role in glucose metabolism. Also it plays a critical role in the T-memory cell immune response (also known as the T-cell antigen CD26) (Merchant et al., 2009). It cleaves an $\mathrm{N}$-terminal dipeptide (Xaa-Pro or Xaa-Ala-) from susceptible peptides. Glucagon- like peptide-1 (GLP-1) and glucose-dependent insulinotropic polypeptide (GIP) are substrates for the ubiquitous proteolytic enzyme DPP and rapidly cleaved by DPP-4 (Holst et al., 2008).

DPP-4 inhibitors are a new class of oral lowering agents for the treatment of T2DM (Fadini \& Avogaro, 2011). They prevent the enzymatic degradation and
Vol. 5 No. 6 (June 2012)

ISSN: 0974- 6846 inactivation of glucagon-like peptide-1 (GLP-1) and glucose-dependent insulinotropic polypeptide (GIP) (Jin Han, 2011). DPP-4 inhibition (1) increases fasting and prandial GLP-1 levels (2) reduces fasting and prandial glucose (3) improves islet $\beta$ and $\alpha$-cell function in T2DM (4) increases $\beta$-cell mass (5) increases insulin sensitivity (6) and reduces glucagon level .Therefore DPP-4 inhibition has the potential of improving glycaemic control.

DPP-4 inhibitors do not cause weight reduction and are associated with a low risk of hypoglycaemia. Also they have not been associated with adverse side effect (Linnebjerg et al., 2008; Ahren, 2009). DPP-4 inhibitors consume as monotherapy or in combination with oral agents (metformin, glitazones, and/or sulphonylureas) and insulin (Deacon \& Holst, 2006). Available DPP-4i inhibitors include sitagliptin, vildagliptin and saxagliptin. Other DPP-4 inhibitors are being developed and soon will reach the market (Fadini \& Avogaro, 2011). Sitagliptin: Sitagliptin (Januvia) was approved by the U.S. Food and Drug Administration (FDA) in October 2006 as monotherapy for the treatment of T2DM. The FDA also approved a sitagliptin / metformin fixed-dose combination in April 2007 as adjunct therapy to diet and exercise to improve glycemic control in adult patients with T2DM (Wua et al., 2009). Sitagliptin is the first DPP-4 inhibitor to reach market and novel agents for therapy of T2DM.

It is an orally active, anti-hyperglycemic agent (AHA) that enhances the effects of the incretin hormones glucose-dependent insulinotropic peptide (GIP) and glucagon like peptide-1(GLP-1) secreted in the intestine in response to food, GIP and GLP-1 have a role in the regulation of glucose homeostasis. Activation of GIP and GLP-1 receptors on pancreatic cells leads to increased levels of cyclic adenosine monophosphate and intracellular calcium, with subsequent glucose-dependent insulin secretion. In addition, sustained receptor activation is associated with insulin biosynthesis and stimulation cell proliferation. Animal and in vitro data further suggest that activation of GIP and GLP-1 receptors promotes cell resistance to apoptosis, proliferation and neogenesis and resulting in enhanced cell function. Additional functions of GLP-1 include inhibition of glucagon secretion from pancreatic cells, resulting in decreased hepatic glucose production, slowing of gastric emptying; suppression of food intake; and enhancement of glucose disposal via neural mechanisms. Sitagliptin is primarily excreted as unchanged drug by the kidneys and therefore renal insufficiency increases circulating levels of sitagliptin (Ahren, 2009). Also sitagliptin has relatively low plasma protein binding (approximately 38\%) (Tahrani et al., 2010).

\section{Monotrapy}

The efficacy of sitagliptin as a monotherapy in patients between the ages of 18 and 75 years with T2DM was examined in a randomized, placebo controlled, 24- 
week, double blind study. The patients $(n=741)$ with a mean baseline $\mathrm{HbA} 1 \mathrm{c}$ of $8.0 \%$ were randomized to receive sitagliptin $100 \mathrm{mg} / \mathrm{d}(n=238)$, sitagliptin $200 \mathrm{mg} / \mathrm{d}$ $(n=250)$ or placebo $(n=253)$. Sitagliptin $100 \mathrm{mg} / \mathrm{d}$ and $200 \mathrm{mg} / \mathrm{d}$ therapy achieved statistically significant efficacy with the placebo subtracted reductions in $\mathrm{HbA1c}$ values from baseline $(-0.79 \%$ and $-0.94 \%$, respectively) (Wua et al., 2009). In a clinical study, 530 patients with $\mathrm{HbA} 1 \mathrm{c}$ $7.5 \%$ and $11.0 \%$ (mean baseline $8.7 \%$ ) received sitagliptin $100 \mathrm{mg}$ once daily or placebo for 18 weeks. Compared with placebo, sitagliptin significantly $(p<$ $0.001)$ reduced mean $\mathrm{HbA} 1 \mathrm{c}(1.0 \%)$, fasting plasma glucose $(1.7 \mathrm{mmol} / \mathrm{L})$ and 2 -h postprandial glucose $(3.1$ $\mathrm{mmol} / \mathrm{L})$.

In this study, sitagliptin monotherapy for 18 weeks significantly improved glycemic control and was welltolerated in patients with T2DM. The primary efficacy hypothesis in this study was that sitagliptin $100 \mathrm{mg}$ once daily would provide greater reduction in $\mathrm{HbA} 1 \mathrm{c}$ than placebo when evaluated after 18 weeks of treatment (Mohan et al., 2009). In a recent study, Sitagliptin (100 mg daily) was initially evaluated as monotherapy in patients with T2DM using different doses for duration of 12 weeks. In this study $(n=555$; mean baseline $\mathrm{HbA} 1 \mathrm{c}$ $7.7 \%)$, HbA1c was reduced by $0.56 \%$ by sitagliptin (Ahren, 2009). A second study $(n=743)$ examined sitagliptin (50 mg twice daily) in patients with a mean baseline $\mathrm{HbA} 1 \mathrm{c}$ of $7.8 \%$. It was found to have reduced $\mathrm{HbA} 1 \mathrm{c}$ over 12 weeks by $0.8 \%$. Furthermore, an 18 -week study comprising 521 patients used sitagliptin at $100 \mathrm{mg}$ or $200 \mathrm{mg}$ once daily and with a mean baseline $\mathrm{HbA} 1 \mathrm{c}$ of $8.1 \%$, it reduced $\mathrm{HbA} 1 \mathrm{c}$ by $0.48 \%$ and $0.60 \%$ (Ahren, 2009).

\section{Combination therapy}

Sitagliptin monotherapies have significant antidiabetic effects, and result in further improvements of glycemic control when given in combination with other drug metformin, sulfonylurea and thiazolidinediones. Sitagliptin has been evaluated in various combination therapies. Most of the identified studies evaluated sitagliptin as add-on therapy to metformin in patients with inadequate glycemic control with metformin (Zerilli et al., 2007). In a clinical study, sitagliptin was administered for 26 weeks in various combinations with metformin after a wash out of previous medication. The combination of the highest doses (100-mg sitagliptin + 2000-mg metformin) resulted in large reductions of $\mathrm{HbA} 1 \mathrm{c}$ with $66 \%$ of the patients reaching values below $7 \%$, which was considered a therapeutic target by the American Diabetes Association.

The combination with metformin is of particular interest because recent studies have indicated that metformin might actually increase GLP-1 biosynthesis and secretion; thus, a greater increase in active GLP-1 concentrations might be obtained with the combination compared with either agent alone. Because of its dual mechanism of action and its impressive efficacy and if the combination can ultimately be demonstrated to prevent deterioration of $\beta$-cell function better than the currently recommended initial treatment (metformin), this combination of $100 \mathrm{mg}$ of sitagliptin and $2000 \mathrm{mg}$ of metformin might be recommended as the initial treatment of newly diagnosed T2DM patients (Holst et al., 2008). Also the combination of metformin and sitagliptin is an effective, safe and well-tolerated treatment for T2DM (Jin Han et al., 2011). In another study, sitagliptin also elicited clinically meaningful reductions in $\mathrm{HbA} 1 \mathrm{c}$ when administered in combination with glimepiride to patients in whom glimepiride alone was unable to provide adequate control (Hermansen et al., 2007).

Vildagliptin: Vildagliptin (previously identified as LAF237, trade names Zomelis, Galvus) was approved in Feb 2008 by European Medicines Agency for use within the EU (Reuters, 2008) and was listed on the Australian PBS with certain restrictions (Reuters, 2008). It is another potent and selective inhibitor of dipeptidyl peptidase-4 (DPP-4) that inhibits the inactivation of GLP-1 (Mentlein et al.,1993) and GIP (Mentlein et al., 1993) by DPP-4, allowing GLP-1 and GIP to potentiate the secretion of insulin in the $\beta$-cells and suppress glucagon release by the $\alpha$ cells of the islets of Langerhans in the pancreas. Vildagliptin has been shown to reduce hyperglycemia in T2DM. Vildagliptin in liver is metabolized to metabolically inactive components, the main one of which is LAY151 and excreted primarily through kidneys with approximately $85 \%$ of the oral dose unchanged in the urine. Also it has a low plasma protein binding of $9.3 \%$ (Tahrani et al., 2010). Vildagliptin has been studied as mono and add on therapy. Vildagliptin, as mono or add on therapy has been shown to reduce $\mathrm{HbA} 1 \mathrm{c}$ with a side effect profile comparable to placebo in most studies, a low incidence of hypoglycaemia and it is largely weight neutral (Tahrani et al., 2010).

\section{Vildagliptin therapy}

In a study, patients with T2DM, following a meal tolerance test, $100 \mathrm{mg}$ of vildagliptin resulted in a significantly higher level of active GLP-1 compared to placebo. A large study $(n=632)$ examined monotherapy with vildagliptin (50 mg once daily, $50 \mathrm{mg}$ twice daily or $100 \mathrm{mg}$ once daily) versus placebo for 24 weeks in subjects with T2DM with a baseline $\mathrm{HbA} 1 \mathrm{c}$ of $8.4 \%$. $\mathrm{HbA} 1 \mathrm{c}$ was reduced by $0.8-0.9 \%$ in the three groups given vildagliptin versus a reduction by $0.3 \%$ in the placebo group. Vildagliptin has also been examined when used in monotherapy (50 mg once daily) for 52 weeks in subjects with T2DM with mild hyperglycaemia ( $\mathrm{HbA} 1 \mathrm{c}$ 6.2-7.2\%) .When adjusted for placebo, vildagliptin reduced $\mathrm{HbA} 1 \mathrm{c}$ by $0.3 \%$. The study was followed by a $52-$ week extension period in 131 patients. Following the 2year period in these patients, $\mathrm{HbA} 1 \mathrm{c}$ was reduced by $0.5 \%$ by the use of vildagliptin (Ahren, 2009). Finally, subjects with impaired glucose tolerance (IGT) treated for 12 weeks with vildagliptin at $50 \mathrm{mg}$ once daily $(n=90)$ versus placebo $(n=89)$, vildagliptin improved glycaemia 
as was evident by the reduced prandial glycaemia following a test meal (Ahren, 2009). In patients with T2DM, 28 day treatment with twice-daily vildagliptin at doses of 10,25 and $100 \mathrm{mg}$ showed a rapid inhibition of DPP-4 activity in all doses. Twelve weeks of vildgliptin 50 mg twice-daily in patients with T2DM suppressed plasma DPP-4 activity from $8.7 \pm 0.58$ to $0.35 \pm 0.07 \mathrm{mU} / \mathrm{ml} \mathrm{min}$ (Tahrani et al., 2010).

\section{Combination with methformin}

In a study, diabetic patients had been on metformin treatment for a mean of 29 months. The results showed that during the initial 12-week core study period, $\mathrm{HbA1c}$ levels in the vildagliptin/ metformin group $(n=56)$ was reduced by $0.7 \%$ compared to the placebo/metformin group $(n=51)$. During the following 40-week extension period, $\mathrm{HbA} 1 \mathrm{c}$ increased by $0.066 \%$ per month in placebo/ metformin group $(n=29)$ but only by $0.013 \%$ per month in vildagliptin/metformin group $(n=42)$. The study also showed that the addition of vildagliptin to patients treated with metformin could effectively prevent deterioration of glycemic control (Wu et al., 2009). In a clinical study, 57 diabetic patients (vildagliptin plus metformin, $n=31$; metformin plus placebo, $n=26$ ) were chosen. The conclusion indicated that $\mathrm{HbA1c}$ and FPG decreased in the vildagliptin/metformin group while these indicators increased in the placebo/metformin group. In addition the post-meal insulin sensitivity was significantly increased in the vildagliptin/metformin group compared to the placebo/metformin group (Wu et al., 2009). In another study, reduction of $\mathrm{HbA1c}$ (by $1.1 \%$ ) after a 24-week combination therapy with vildagliptin (100 mg once daily) and metformin was reported in patients $(n=362)$ with a mean baseline $\mathrm{HbA} 1 \mathrm{c}$ of $7.5 \%$ (Ahren, 2009).

\section{Combination with insulin}

In a study, vildagliptin (50 mg twice daily) combined with insulin treatment ( $80 \mathrm{U}$ per day) reduces $\mathrm{HbA} 1 \mathrm{c}$ levels by $0.5 \%$ (baseline $8.5 \%$ ) versus a reduction of $0.2 \%$ with placebo. However, despite the improvements in glycemic control, significantly fewer hypoglycemic events were observed in patients receiving the combination therapy. Thus, by combining insulin therapy with a glucose dependent agent (e.g. a DPP-4 inhibitor) it might be possible to reduce $\mathrm{HbA} 1 \mathrm{c}$ levels, which cannot be achieved with insulin alone without increasing the risk of hypoglycemia (Holst et al., 2008). In another study, a 24-week trial examined the effect of vildagliptin $(n=144$; $50 \mathrm{mg}$ twice daily) and placebo $(n=152)$ when added to insulin therapy. The patients were inadequately controlled by insulin $(\mathrm{HbA} 1 \mathrm{c}=7.5-11 \%)$. The results suggested that vildagliptin in combination with insulin reduced $\mathrm{HbA1c}$ by $0.7 \%$, whereas insulin alone reduced $\mathrm{HbA} 1 \mathrm{c}$ only by $0.2 \%$ (Wua et al., 2009).

\section{Combination with glimepiride}

A 24-week study examined vildagliptin (50 mg once or twice daily) versus placebo when added to glimepiride (4 mg daily) in 515 patients with a mean baseline $\mathrm{HbA} 1 \mathrm{c}$ of mean $8.5 \%$ (Garber et al., 2008) HbA1c was reduced by
$0.6 \%$ by vildagliptin at $50 \mathrm{mg}$ once daily and $0.76 \%$ at 50 $\mathrm{mg}$ twice daily. Another placebo-controlled study examined the add-on of sitagliptin (100 mg daily) to glimepiride alone or glimepiride and metformin in patients $(n=441)$ with a mean baseline $\mathrm{HbA1c}$ of $8.3 \%$. In the end, reduction in $\mathrm{HbA} 1 \mathrm{c}$ was $0.7 \%$ in patients given sitagliptin and glimepiride and $0.9 \%$ in patients given triple therapy (Hermansen et al., 2007).

Saxagliptin: Saxagliptin was approved by the US Food and Drug Administration (FDA) in July 2009 and by the European Medicines Evaluation Agency in October 2009 for use as monotherapy or in combination regimens for the treatment of T2DM. It is another potent inhibitor of dipeptidyl peptidase-4 (DPP-4). It is metabolized hepatically by cytochrome P450 (CYP) to an active metabolite, 5-hydroxy saxagliptin (Aren, 2009). This active metabolite is also a selective, reversible, competitive DPP-4 inhibitor, but it is half as potent as saxagliptin (Fura et al., 2009; Dhillon \& Weber, 2009). Having an active metabolite is a unique feature of saxagliptin compared with other DPP-4 inhibitors. Saxagliptin, used as monotherapy and in combination regimens, has been associated with significant reductions in $\mathrm{HbA} 1 \mathrm{c}$ and significant increases in the rate of achieving target $\mathrm{HbA} 1 \mathrm{c}$ in patients with T2DM Deanna et al. (2011).

\section{Monotherapy}

In a clinical study, oral saxagliptin 2.5 or $5 \mathrm{mg}$ once daily suppressed DPP4 activity for 24 hours (New drug, 2011), significantly improving mean HbA1c levels (relative to placebo) in well designed, 24-week trials in treatment-naive patients with T2DM (Dhillon \& Weber, 2009). In a multicenter, randomized, double-blind, placebo-controlled trials, 338 patients with a mean baseline $\mathrm{HbA} 1 \mathrm{c}$ of $7.9 \%$ were randomly assigned to receive 1 of 5 of saxagliptin doses $(2.5,5,10,20$, or 40 $\mathrm{mg}$ or placebo) once daily for 12 weeks. After 12 week, $\mathrm{HbA1c}$ was significantly different from baseline in all of the saxagliptin treatment arms compared with placebo. In another study, after 2 weeks of once-daily dosing of saxagliptin in healthy subjects and in patients with T2DM, plasma DPP-4 was inhibited. Based on in vitro data, saxagliptin exhibits greater inhibition of DPP-4 than either sitagliptin or vildagliptin at physiologic temperatures (Deanna et al., 2011).

\section{Combination therapy}

When saxagliptin was used in combination with metformin for 24 weeks, the adjusted mean reductions from baseline in $\mathrm{HbA} 1 \mathrm{c}$ and the proportions of patients achieving target $\mathrm{HbA1c}(\leq 7.0 \%)$ were significantly greater with saxagliptin-metformin compared with monotherapy with either drug (all, $P \leq 0.0001$ ). When saxagliptin was used in combination with a sulfonylurea or a thiazolidinedione, the changes in $\mathrm{HbA} 1 \mathrm{c}$ ranged from $-0.54 \%$ to $-0.64 \%$ and $-0.66 \%$ to $-0.94 \%$, respectively, in a dose-dependent manner $(P \leq 0.0007$ vs monotherapies) (Deanna et al., 2011). In another study, 
combination therapy with saxagliptin $5 \mathrm{mg}$ once daily and metformin was more effective than saxagliptin or metformin monotherapy (Dhillon \& Weber, 2009). When the relative benefits of increasing the dose of a sulfonylurea or adding saxagliptin were assessed in a study of 768 patients, combination treatments were shown to have a significantly greater impact on fasting blood glucose than increasing the tested glibenclamide dose alone (New drug, 2011).

\section{Conclusion}

The number of antidiabetes drugs is increasing as our understanding of the physiology of T2DM develops. GLP-1 and its derivatives are the latest marked development in this field. Both GLP-1 analogues such as exendin, liraglutide and DPP-IV inhibitors such as sitagliptin, vildagliptin and saxagliptin effectively improve metabolic control in patients with T2DM. Both seem to be effective in monotherapy and in combination with other anti-diabetic agents. DDP-IV inhibitors are administered orally, whereas the analogues require parenteral administration. The analogues cause significant reductions in body weight, whereas the inhibitors seem to be weight neutral. Now the long-term durability and effects on long-term end points are required for this class of compounds.

\section{Reference}

1. Agerso $H$ and Vicini $P$ (2003) Pharmacodynamics of NN2211, a novel long acting GLP-1 derivative. Europ. J. Pharmaceut. Sci. 19, 141-150.

2. Ahren B (2009) Clinical results of treating type 2 diabetic patients with sitagliptin, vildagliptin or saxagliptin diabetes control and potential adverse events. Best Pract. Res. Clin. Endocrinol. Metabol. 23, 487-498.

3. Akansha Mishra, Jaitly AK and Arvind K. Srivastava (2009) Antihyperglycaemic activity of six edible plants in validated animal models of diabetes mellitus. Indian J.Sci.Technol. 2 (4), 80-86. Domain site: http://www.indjst.org.

4. Bradley DP and Kulstad R (2010) Exenatide and weight loss. Nutr. 26, 243-249.

5. Bunck MC, Diamant M, Cornner A, Eliasson B, Malloy $\mathrm{JL}$ and Shaginian RM (2009) One-year treatment with exenatide improves beta cell function, compared with insulin glargine, in metformin-treated type 2 diabetic patients. Diabetes Care. 32, 762-768.

6. Chen J, Couto FM, Minn AH and Shalev A (2006) Exenatide inhibits b-cell apoptosis by decreasing thioredoxin-interacting protein. Biochem. Biophys. Res. Comm. 346, 1067-1074.

7. Combettes M (2006) GLP-1 and type 2 diabetes: physiology and new clinical advances. Curr. Opin Pharmacol. 6,598-605.

8. Deacon CF and Holst JJ (2006) Dipeptidyl peptidase IV inhibitors: A promising new therapeutic approach for the management of type 2 diabetes. Int. J. Biochem. Cell Biol. 38, 831-844.

9. Deacon CF, Johnsen AH and Holst JJ (1995) Degradation of glucagon-like peptide- 1 by human plasma in vitro yields an $\mathrm{N}$-terminally truncated peptide

\section{Vol. 5 No. 6 (June 2012) ISSN: 0974-6846}

that is a major endogenous metabolite in vivo. J. Clin. Endocrinol. Metab. 80, 952-957.

10. Deacon CF, Nauck MA, Meier J, Hücking $K$ and Holst JJ (2000) Degradation of endogenous and exogenous gastric inhibitory polypeptide in healthy and in type 2 diabetic subjects as revealed using a new assay for the intact peptide. J. Clin. Endocrinol. Metab. 85, 35753581.

11. Deanna S, Kania DS and Gonzalvo JD (2011) Saxagliptin: A clinical review in the treatment of type 2 diabetes mellitus. Clin. Therapeut. 6,1-18.

12. Dhillon S and Weber J (2009) Saxagliptin. Drugs. 69, 2103-2114.

13. Drucker DJ (2006) The biology of incretin hormones. Cell Metab. 3, 153-165.

14. Fadini GP and Avogaro A (2011) Cardiovascular effects of DPP-4 inhibition: Beyond GLP-1.Vasc. Pharmacol. pp: 7.

15. Faludi P, Brodows R, Burger J and Ivanyi T (2009) The effect of exenatide re-exposure on safety and efficacy. Peptides. 30, 1771-1774.

16. Fehmann HC, Goke R and Goke B (1995) Cell and molecular biology of the incretin hormones glucagon-like peptide-I and glucose-dependent insulin releasing polypeptide. Endocr. Rev.16, 390-410.

17. Fura A, Khanna A, Vyas V, Chang SY, Caporuscio C, Boulton DW and Christopher Kirby M (2009) Pharmacokinetics of the dipeptidyl peptidase 4 inhibitor saxagliptin in rats, dogs, and monkeys and clinical projections. Drug Metab. Dispos. 37, 1164-1171.

18. Garber A, Henry R, Ratner HR and Garcia- Hernandez PA (2009) Liraglutide versus glimepiride monotherapy for type 2 diabetes (LEAD-3 Mono): a randomised, 52week, phase III, double-blind, parallel-treatment trial. Lancet. 373, 473-481.

19. Garber AJ, Foley JE, Banerji MA, Ebeling $P$, Gudbjörnsdottir S, Camisasca RP, Couturier A, Baron MA (2008) Effects of vildagliptin on glucose control in patients with type 2 diabetes inadequately controlled with a sulphonylurea. Diabetes Obes. Metabol. 10, 1047-1056.

20. Harder H, Nilson L, Tu DT and Astrup A (2004) The effect of liraglutide, a long-acting glucagon-like peptide 1 derivative, on glycemic control, body composition, and 24-h energy expenditure in patients with type 2 diabetes. Diabetes Care. 27, 1915-1921.

21. Heine RJ, Gaal LF and Johns D (2005) Exenatide versus insulin glargine in patients with suboptimally controlled type 2 diabetes: a randomized trial. Annu. Intl. Med. 143, 559-569.

22. Hermansen K, Kipnes M and Luo E (2007) Efficacy and safety of the dipeptidyl peptidase-4 inhibitor, sitagliptin, in patients with type 2 diabetes mellitus inadequately controlled on glimepiride alone or on glimepiride and metformin. Diabetes Obes. Metabol. 9, 733-745.

23. Holst JJ (2007) The physiology of glucagon-like peptide 1. Physiol. Rev. 87, 1409-1439.

24. Holst JJ and Deacon CF (2004) Glucagon-like peptide 1 and inhibitors of dipeptidyl peptidase IV in the treatment 
of type 2 diabetes mellitus. Curr. Opin. Pharmacol. 4, 589-596.

25. Holst JJ, Deacon CF and Vilsbøll T (2008) Glucagon-like peptide-1, glucose homeostasis and diabetes. Trends Mol. Med. 4,161-169.

26. Jali MV and Hiremath MB (2010) Diabetes. Indian J.Sci.Technol. 3 (10), 1106-1107. Domain site: http://www.indjst.org.

27. Jin Han S, Sung E, Choi SE, Kang $Y$ and Jung JG (2011) Effect of sitagliptin plus metformin on b-cell function, islet integrity and islet gene expression in Zucker diabetic fatty rats. Diabetes Res. Clin. Pract. 92, 213-222.

28. Knudsen LB, Nielsen PF and Huusfeldt PO (2000) potent derivatives of glucagon-like peptide- 1 with pharmacokinetic properties suitable for once daily administration. J. Med. Chem. 43, 1664-1669.

29. FLinnebjerg H, Park S, Kothare PA, Trautmann ME and Kenneth M (2008) Effect of exenatide on gastric emptying and relationship to postprandial glycemia in type 2 diabetes. Regul. Peptides. 151, 123-129.

30. Madsbad S (2009) Exenatide and liraglutide: different approaches to develop GLP-1 receptor agonists (incretin mimetics) preclinical and clinical results. Best Pract. Res. Clin. Endocrinol. Metabol. 23, 463-477.

31. Madsbad S, Schmitz O, Ranstam J, Jakobsen G and Matthews DR (2004) Improved glycemic control with no weight increase in patients with type 2 diabetes after once-daily treatment with the long-acting glucagon-like peptide 1 analog liraglutide (NN2211): a 12-week, double-blind, randomized, controlled trial. Diabetes Care. 27, 1335 - 42.

32. Mannucci E and Rotella CM (2008) Future perspectives on glucagon-like peptide-1, diabetes and cardiovascular risk. Nutr. Metabol. Cardiovasc. Dis.18, 639-645.

33. Marfellaa R, Barbieri M, Grella R, Rizzo MR (2010) Effects of vildagliptin twice daily vs. sitagliptin once daily on 24-hour acute glucose fluctuations . J. Diabetes Complications. 24, 79-83.

34. Mayhew MS (2008) Diabetes management and exenatide. J. Nurse. Pract. 4(9), 706-707.

35. Mentlein R, Gallwitz B and Schmidt WE (1993) Dipeptidyl-peptidase IV hydrolyses gastric inhibitory polypeptide, glucagon-like peptide-1(7-36) amide, peptide histidine methionine and is responsible for their degradation in human serum. Eur. J. Biochem. 214, 829-835.

36. Merchant M, Monroe C and Falconi F (2009) Dipeptidyl peptidase IV activity in the blood of the American alligator. Comp. Biochem. Physiol.15, 341-345.

37. Mohan V, Yang W, Ho-Young $S$ and $X u$ L (2009) Efficacy and safety of sitagliptin in the treatment of patients with type 2 diabetes in China, India, and Korea. Diabetes Clin. Practice. 83,106-11 6.

38. Nauck MA and Meier JJ (2005) Glucagon-like peptide 1 and its derivatives in the treatment of diabetes. Regul Peptides. 128,135-148.

39. Nauck MA, Duran S, Kim D, John D, Northrup J, Festa A, Brodows R and Trautmann M (2007) A comparison of twice-daily exenatide and biphasic insulin aspart in

\section{Vol. 5 No. 6 (June 2012) ISSN: 0974-6846}

patients with type 2 diabetes who were suboptimally controlled with sulfonylurea and metformin:a noninferiority study. Diabetologia. 50, 259-67.

40. New Drugs (2011) Saxagliptin. Australian Prescriber. 34, 89-91.

41. Nielsen LL (2005) Incretin mimetics and DPP-4 inhibitors for the treatment of type 2 diabetes. DDT. 10, 703-801.

42. Pushpa S. Patil, Umesh R. Dixit and Baru Dhruvkumar Hiralal (2011) Study of diabetes in Dharwad- an urban area in India. Indian J.Sci. Technol. 4 (11), 1481-1483. Domain site: http://www.indjst.org.

43. Tahrani AA, Kennedy A and Barnet AH (2010) Glycaemic control in type 2 diabetes: Targets and new therapies. Pharmacol. Therapeut. 125, 328.

44. Ugleholdt R, Poulsen ML, Holst PJ, Irminger JC, Orskov CO and Pedersen J (2006) Prohormone convertase 1/3 is essential for processing of the glucose-dependent insulinotropic polypeptide precursor. J. Biol. Chem. 281, 11050-11057.

45. Urusova IA, Farilla L and Hui H (2004) GLP-1 inhibition of pancreatic islet cell apoptosis. Trends Endocrinol. Metabol. 15, 27-30.

46. Venkatesan P, Dharuman C and Gunasekaran S (2011) A comparative study of principal component regression and partial least squares regression with application to FTIR diabetes data. Indian J.Sci.Technol. 4 (7), 740746.

47. Vilsboll T and Holst JJ (2004) Incretins, insulin secretion and type 2diabetes mellitus. Diabetologia. 47, 357-366.

48. Vilsboll T, Agerso H, Krarup T and Holst JJ (2003) Similar elimination rates of glucagon-like peptide- 1 in obese type 2 diabetic patients and healthy subjects. J. Clin. Endocrinol. Metab. 88, 220-224.

49. Wild S, Roglic G, Green A, King H and Sicree R (2004) Global prevalence of diabetes: estimates for the year 2000 and projections for 2030. Diabetes Care. 27, 1047-1053.

50. Winzell SM and Ahren B (2007) G-protein-coupled receptors and islet function-implications for treatment of type 2 diabetes. Pharmacol. Therapeut. 116, 437-448.

51. Wua J, Chenb Y, Shia X, Gua W (2009) Dipeptidyl peptidase IV (DPP IV): a novel emerging target for the treatment of type 2 diabetes. J. Nanjing. Med. Univ. 23, 228-235.

52. Yong Jin H, Liu WJ and Park JH (2010) Effect of Dipeptidyl Peptidase-IV (DPP-IV) Inhibitor (Vildagliptin) on Peripheral Nerves in Streptozotocin-induced Diabetic Rats. Arch. Med. Res. 40, 536-544.

53. Zerilli T and Pyon EY (2007) Sitagliptin Phosphate: A DPP-4 Inhibitor for the Treatment of Type 2 Diabetes Mellitus. USA. Reproduction in whole or part is not permitted. Excerpta. Med. 29(12), 2614-2634.

54. Zinman B, Hoogwerf BJ and Duran GS (2007) The effect of adding exenatide to a thiazolidinedione in suboptimally controlled type 2 diabetes: a randomized trial. Annu. Int. Med. 146, 477-485. 